TITLE:

\title{
Perceived incentives to transdisciplinarity in a Japanese university research center
}

$\operatorname{AUTHOR}(S)$ :

Lauto, Giancarlo; Sengoku, Shintaro

CITATION:

Lauto, Giancarlo ...[et al]. Perceived incentives to transdisciplinarity in a Japanese university research center. Futures 2015, 65: 136-149

ISSUE DATE:

2015-01

URL:

http://hdl.handle.net/2433/196093

RIGHT:

(c) 2014 Elsevier Ltd. NOTICE: this is the author's version of a work that was accepted for publication in Futures. Changes resulting from the publishing process, such as peer review, editing, corrections, structural formatting, and other quality control mechanisms may not be reflected in this document. Changes may have been made to this work since it was submitted for publication. A definitive version was subsequently published in Futures, 65, 2015,

doi:10.1016/j.futures.2014.10.010; This is not the published version. Please cite only the published version.; この論文は 出版社版でありません。引用の際には出版社版をご確認ご利用ください。 
Perceived incentives to transdisciplinarity in a Japanese university research center

\title{
Highlights
}

We examine research strategies in a transdisciplinary research center in Japan

Only a minority of scientists prioritizes transdisciplinary research

Choice of a research strategy relates with both intellectual and career motivations Junior scientists experience contradictions between intrinsic and extrinsic rewards Activity-based evaluation and dedicated career paths may promote transdisciplinarity

\begin{abstract}
As a method of investigating complex socially relevant phenomena, transdisciplinary research (TDR) is gaining increasing centrality as a model of knowledge production. However, it is being discouraged by a scientific reward system based on disciplinary logic. The disincentive is even stronger for junior scholars who should be developing the capabilities necessary for achieving long-term scientific excellence.

Building on theories of the coordination of scientific communities and using the case of a research center of Kyoto University investigating the boundary between cell and material sciences, we aim to disentangle the interplay between institutional incentives and intrinsic motivation in the prioritization of TDR over monodisciplinary research.

We find that, despite strong interest in TDR among scientists and the center's mission to promote this orientation, only a minority of scientists prioritize this approach. Choice of research strategy is associated with its perceived benefits for idea generation, publication opportunities, intellectual effort required, the costs of team coordination, and satisfaction with organizational resources. Furthermore, the propensity to prioritize TDR drops among scientists beginning their careers.

Therefore, we recommend the development of evaluation schemes grounded in activity-based measures and the granting of permanent positions to scientists pursuing TDR.
\end{abstract}

Keywords: transdisciplinarity; university research center; research incentives; academic career; life science; material science; Japan

\section{Introduction}

In many fields, such as the life and material sciences, investigations are targeting increasingly complex phenomena, a tendency triggered by policy pressures encouraging studies with direct implications for major societal issues and industrial innovation and enabled by novel and powerful instrumentation that is broadening the scope of research [1-4].

Transdisciplinary research (TDR) is often called for in these investigations, since individual disciplines offer only partial views of the issues at stake. The literature offers several 
conceptualizations of TDR, possibly reflecting its heterogeneity and dynamism. The concept of TDR encompasses a great variety of research practices that all share an orientation towards a societal problem, interdisciplinarity, and stakeholder involvement [2,5-13].

This paper contrasts transdisciplinary with monodisciplinary research (MDR), which is conducted without the involvement of external actors and aims to deepen the theoretical understanding and applications of discoveries within one well-defined disciplinary area.

It is expected that TDR will soon gain increasing centrality as a model of knowledge production, challenging established disciplinary practices $[14,15]$. Accordingly, several incentive schemes and training programs have been launched $[8,15,16]$, while novel organizational forms such as "university research centers" have been designed to provide a setting favorable to TDR [17]. However, this process requires that scientists, research organizations, and scientific systems redefine their priorities and build new research capabilities [18]. This process seems problematic because science policy stimuli and scientists' preference for TDR may conflict with the established scientific criteria of quality, which are based on a disciplinary logic that typically rewards MDR. As a consequence, prioritizing non-mainstream approaches such as TDR is a rather risky strategy for scientists wanting to improve their professional standing $[7,14,19]$. This is especially critical for junior scientists, who are expected to cultivate the transdisciplinary capabilities necessary for the long-term development of scientific systems but at the same time face tenure and career pressures.

We build on theories of the coordination of scientific communities [20-26] to develop a series of propositions on the factors influencing the choice of transdisciplinary research strategy. We identify the factors scientists perceive as being conducive to the pursuit of each of three research strategies: prioritization of TDR, prioritization of MDR, and equal importance given to both. Our study contributes to the debate on TDR by providing new evidence on the 
interplay between external incentives and individual preferences in the definition of a research strategy. Moreover, we explore these issues in an empirical setting that has been under-researched.

Our study focuses on the Institute for Integrated Cell-Material Sciences (WPI-iCeMS), a university research center at Kyoto University, Japan. The center was established through the government-funded World Premier International Research Center Initiative program to contribute to the emerging field of cell-material sciences. We believe this case to be worthy of attention for several reasons. First, the Japanese research system has recently undergone profound changes driven by policies designed to encourage the diffusion of practices and organizational models for sustaining TDR, such as an orientation towards societal challenges, disciplinary integration, collaborative projects with industry, and the creation of world-class research centers [27-29]. Our study offers insights into this ongoing systemic transformation. One distinctive feature of the Japanese research system that seems to persist despite these changes is the fact that full professors enjoy a high level of autonomy and protection. While such employment conditions may lead to conservative or inefficient behaviors, they may also stimulate senior faculty at world-class organizations like WPI-iCeMS to experiment and undertake scientific risks, such as with TDR. Therefore, WPI-iCeMS offers a methodological opportunity to observe how the interplay among the organizational context and the intrinsic and extrinsic motivations for TDR varies across levels of seniority and academic rankings characterized by different levels of security. Finally, we believe that analyzing a Japanese case adds to our understanding of the organization of university research centers, the literature on which has focused mainly on the American experience [30-34].

We carried out a survey on scholars working at WPI-iCeMS as well as in-depth interviews with selected scientists concerning their self-reported orientation towards TDR, their motivations and perceived opportunities, and the constraints associated with this approach. 
Our respondents report a generally positive attitude towards TDR, which is, however, prioritized by only a minority. Resistance is found particularly among those who have just entered academia. We also find that TDR or MDR prioritization is associated with a comparison of its potential benefits in terms of research insights and potential barriers to career development, as well as with the availability of research resources. Our study emphasizes the necessity of developing research evaluation systems and career paths consistent with the science policy goal of strengthening research systems' transdisciplinary capabilities.

The rest of this paper is organized as follows. Section 2 outlines the theoretical framework, examining how the governance of scientific communities and organizational-level practices affect research strategizing, particularly in the context of university research centers. Section 3 presents the research design, while the key results are presented in Section 4. Finally, we present the concluding remarks and discuss the study's limitations and implications in Section 5.

\section{The drivers of TDR prioritization}

\subsection{The selection of a research strategy}

We refer to a "research strategy" as the set of decisions researchers make concerning the domains of the scientific discourse they wish to enter; these decisions constitute the core process of the production of scientific knowledge (i.e., topics to investigate, methodologies to adopt, and collaborators to partner with). Different strategies are associated with different epistemic communities, potential for reputational gains, risk of failure, required capabilities, and research technologies [21]. To prioritize (i.e., systematically pursue in the medium to long term) TDR, MDR, or neither can therefore be considered three different strategic choices, since they entail notable differences in terms of all the aforementioned dimensions. We are 
aware that dichotomizing research strategies (TDR vs. MDR) simplifies the complexity of actual research practices, particularly in emerging and fast-developing fields. However, we believe it useful to distinguish among the features of alternative models of knowledge production, in line with other conceptualizations, such as Mode-1 and Mode-2 science [2].

This paper defines TDR broadly as a scientific approach that aims at generating knowledge useful for solving complex problems relevant to societal actors by applying an interdisciplinary method (i.e., by aggregating and integrating theories and/or evidence and/or methods developed in various disciplinary domains). An additional feature of TDR is the participation of external stakeholders in research activities, which may manifest in many ways, including through support for and legitimacy to the projects, or even through direct influence on their goals [2,5-13]. This choice allows us to capture the complexity of the phenomenon while requiring us to consider heterogeneous research practices.

To understand scientists' selection of research strategy, we follow Osterloh and Frey $[35,36]$, who include insights drawn from psychological economics in a conceptual framework that traditionally underpins the governance of academic research. The latter perspective rests on principal-agent theory [37] as developed in the new public management approach [38-41] and on the economics of science $[23,25]$. According to this view, scientists define their research agenda by comparing the benefits of being recognized by their peers for solving an intellectual problem to the effort required by the task and the perceived scientific competition in that problem area [20-23]. Sets of objective measures, based mainly on publication and citation rates, are used to evaluate scientists' performance and to assist crucial decisions such as promotion and compensation because they are regarded as effective methods of aligning scholars' goals with those of the research organizations $[35,39,42]$. However, it should be recognized that not all scientists react to these incentives in the same way, as career goals and motivations vary within the scientific community $[43,44]$. Indeed, in addition to professional 
freedom, the satisfaction of intellectual curiosity, and the pleasure in applying and disseminating knowledge $[23,45,46]$, the desire to directly contribute to social progress is also an important driver for many scientists. For them, engaging in problem-oriented research with non-scientific stakeholders represents a way to attribute meaning to their work [47], given the long delay between scientific advances and impacts on practice[48].

\subsection{Factors associated with knowledge production}

We submit that a primary criterion in research strategy selection is the potential for idea generation, since creativity and the ability to develop original insights are features of all research activity [23], regardless of motivation. Both TDR and MDR may be fruitful for this purpose: the former pursues idea generation through the hybridization of insights and methods across fields, while the latter proceeds through a deeper, more fine-grained understanding of problems.

Specifically, TDR requires the integration of diverse cognitive inputs and the involvement of partners at non-academic institutions. The interplay of cognitive and institutional diversity generates a need for coordination of collaborative research that can be addressed by balancing these two dimensions of diversity [49] through the use of appropriate strategies for acquiring and integrating knowledge [50] and by relying on organizational mechanisms for project coordination [51].

While cognitive diversity is necessary for the generation of original insights and the analysis of complex problems, its efficacy diminishes as the distance among disciplinary areas grows because of the learning process costs at the individual, project team, and laboratory levels necessary to master the concepts, methods, and techniques employed in other disciplines [52]. Investigations across established disciplinary boundaries require scientists to develop a new set of skills, different from those acquired through traditional research training, and an 
intimate knowledge of all the perspectives being used $[7,8]$. Furthermore, in the fields at the core of our investigation, scientists need to acquire new scientific capabilities when employing research technologies developed in different fields, especially if their use requires considerable tacit knowledge [50]. Additional constraints emerge in collaborative projects involving researchers with different specializations, when teams must perform mutual adjustments and develop a shared language in order to operate.

These difficulties intensify when the project requires the contribution of scientists belonging to several communities or institutional settings (e.g., academia and industry) that differ in their goals, values, standards, and formal and informal rules. Furthermore, these drawbacks are exacerbated when physical distance impedes the face-to-face interaction on which trustbased relationships are based. Therefore, scientists involved in a multi-institutional collaborative project need to negotiate their priorities, smooth divergences in work practices, and invest in the adoption of appropriate coordination mechanisms $[15,16,49-56]$.

We may therefore expect that scientists who perceive the intellectual costs of executing TDR to be manageable will be more inclined to this type of investigation.

Thus, we formulate Proposition-1: scientists' choice of research strategy is associated with its perceived benefits in terms of idea generation. We further posit Proposition-2: scientists' choice of research strategy is associated with its perceived required intellectual effort and the perceived cost of coordinating its collaborative undertaking.

\subsection{Incentives at the scientific community level}

Studies in the economics and the sociology of science emphasize that the publication system serves as a coordination mechanism for scientific knowledge production: by rewarding scholars who disclose findings that contribute to the development of a field, the publication 
system highlights the issues relevant for a scientific community and informs scholars of the most promising research strategies [23-26]. The use of publications for evaluation motivates scientists to pursue the research strategies most conducive to publication in prestigious journals and to obtain recognition through citations. As mentioned, TDR tends to be associated with a lower reputational standing because scientific communities often adopt disciplinary criteria to evaluate transdisciplinary studies despite the fact that these entail different notions of relevance [6,16]. Studies across disciplinary boundaries are often criticized for their inadequate understanding of the disciplinary discourses employed [12]. As a consequence, highly recognized journals seem to be biased against TDR [19], and it has been found that, in the life sciences, articles spanning disciplinary boundaries tend to receive fewer citations [57]. Though these pressures are most relevant for researchers pursuing scientific excellence as a goal, they also concern all members of the scientific community.

Based on these considerations, we formulate Proposition-3: scientists' choice of research strategy is associated with its perceived barriers to publication opportunities.

\subsection{Incentives at the organization level}

Motivated by the pursuit of social accountability, research organizations are increasingly adopting strategic planning and human resource management practices designed to direct scientists' efforts and research agendas to specific goals [29,40-42,58]. Reward systems designed at the site level contribute to the formation of the organizational culture and can thus be considered part of the social norms influencing scholars' decision making. These social norms may either reinforce the goals of a broader scientific community or offer alternative ones.

We argue that scientists at university research centers experience a conflict between commitment to the goals of their employing organization and the pursuit of research 
strategies that may increase employment opportunities in the broader job market. In fact, university research centers are organizational units within universities, distinct from departments, which pursue research issues relevant for innovation or societal change. Their unique organizational features - such as an explicit scientific mission, a faculty chosen from different departments, dedicated research facilities, less demanding teaching and administrative obligations, and formalized partnerships with other research organizationsoffer scientists a broader array of goals than are available in "traditional" academic settings. Indeed, these environments are found to be conducive to TDR [17,32,59].

However, the performance criteria more relevant for university research centers-those referring to TDR, technology transfer, and collaboration-may incentivize scientists to focus on problems and issues that diverge from disciplinary research, which, as we have seen, ensure reputational gains in the broader scientific community $[19,55,60]$. In order to offset these obstacles to TDR, university research centers provide scientists with facilities, funding, human resources, and support services explicitly targeted to this approach. Empirical studies conducted in various contexts show that these organizations foster investigations across disciplinary and institutional boundaries [30-34], while their effect on scientific productivity is unclear (see e.g., [30] and [31,61]).

We thus formulate Proposition-4: scientists' choice of research strategy is influenced by the resources and influence offered by their employing organization.

\subsection{The influences of the academic life cycle}

The challenges of TDR outlined in the previous sections suggest that this strategy is a better fit for scientists who are endowed with greater scientific and social capital and are less sensitive to career pressures; junior scholars seek to obtain status and recognition in their community prior to engaging in problem-oriented research $[21,47,48,53,62,63]$. These 
theoretical expectations have been supported by empirical studies conducted in other contexts that provide useful indications concerning the drivers of research strategies. Studies have found TDR to be positively associated with scientists' experience and employment in both academia and industry [55]. Perceptions of the advantages of TDR for career advancement grow according to academic ranking: senior scholars have the most favorable view of TDR, together with graduate students, who, however, seem to be aware of its possible long-term drawbacks [64]. Research has found that junior scholars who defend an interdisciplinary doctoral dissertation are disadvantaged in achieving tenure [65], and affiliation with problem-oriented university research centers has been found to be more beneficial to senior faculty $[66,67]$, though one study [30] finds that junior scientists experience greater gains in productivity after affiliation.

Guided by these arguments, we formulate Proposition-5: scientists' choice of research strategy varies across seniority levels, with more senior scholars tending to prioritize TDR over MDR.

Table 1 summarizes the propositions investigated in our study.

\section{$===$ PLEASE, INSERT TABLE 1 ABOUT HERE ===}

\section{Research design}

\subsection{Empirical setting}

The empirical setting of this study is WPI-iCeMS (www.icems.kyoto-u.ac.jp/e/about/), a university research center at Kyoto University, from which it enjoys a high degree of scientific and administrative autonomy. It is one of the centers funded through the World Premier International Research Center Initiative (WPI), a program initiated in 2007 by the Ministry of Education, Culture, Sports, Science and Technology (MEXT) of Japan to promote TDR and 
international collaboration, achieve an outstanding research environment that attracts frontline researchers from around the world, and revolutionize conventional modes of research operation and administration. The program investigates the intersection of existing disciplinary fields in order to produce major scientific breakthroughs relevant to critical longterm issues for Japanese society such as its ageing population and low birth rate in a context of prolonged economic stagnation. The WPI Program runs nine institutes with JPY 10.1 billion of public budgetary support. It is well implemented through Japan's science and technology policy framework body and is internationally recognized as a representative case of TDR. The WPI centers play a key role in the generation of a transdisciplinary capability through the training and development of junior researchers. Indeed, one of the missions of WPI-iCeMS is to become a "global hub for career development for scientists" $[29,68]$. Thus, it represents an appropriate setting for an analysis of the interplay between organizational, career, and scientific incentives for TDR.

WPI-iCeMS aims to integrate physics, chemistry, and cell biology. Kyoto University has strong expertise in each of these disciplines, and WPI-iCeMS plans to leverage these strengths to develop a meso-scale field between the material and life sciences. The center's research contributes to human wellness in environmentally friendly chemistry and regenerative medicine by controlling stem cells through smart medicine.

The WPI-iCeMS facility comprises 18 laboratories covering several specializations in the life and material sciences, such as biomaterial science, chemical biology, nano-biotechnology, and stem cell biology. The laboratories feature researchers and technicians with different seniorities and rankings and led by a principal investigator. The institute adopts a system of academic ranking according to which some of full and associate professors are tenured, while all assistant professors, lecturers, and post docs are untenured. Laboratories also include PhD candidates and other graduate students not enrolled in a doctoral program. 
The WPI-iCeMS' management system monitors scientific performance as well as job satisfaction. It has implemented a series of human resource management initiatives to strengthen both scientific excellence and the transdisciplinary nature of the center [29]. Candidates for the position of researcher or principal investigator at WPI-iCeMS must undergo a comprehensive evaluation of their academic profile, including their ability to perform cross-disciplinary investigation, attract research grants, and develop long-term research plans. The center thus fosters its transdisciplinary capabilities and orientation. Advancement up the ladder is achieved based on academic excellence, as manifested especially in the publication of research papers in high quality journals as well as in contributions to the laboratory and to the overall mission of the WPI-iCeMS. This includes TDR, even though enrollment procedures do not explicitly mention collaborations with industrial or societal stakeholders. The center promotes investigations across disciplinary boundaries by awarding a prize to scientists whose studies address social challenges, providing opportunities for knowledge sharing among scientists working in different units of the center, international mobility schemes, and meetings across laboratories. Moreover, the center's visibility in the domestic and international scientific communities helps improve scientists' professional standing and exposes them to employment opportunities. Thus, this research setting provides us with the opportunity to analyze a population of scientists who share social norms favorable to TDR and who have the chance to pursue top-level international careers.

Scientists at different levels of the academic hierarchy may attribute different meanings to the notion of TDR. Indeed, team leaders-responsible for outlining the scope and priorities of their group's research-have more freedom than do other scientists to investigate issues that may have social implications and to specify the intensity and forms of external stakeholders' interactions during research projects. All researchers are fully empowered regarding the 
choice of theoretical and methodological apparatus for their investigations. Therefore, more senior scientists may craft their research strategies along all the dimensions of TDR, while most of the other scientists may be primarily concerned with the interdisciplinary dimension.

Our empirical strategy is articulated into two steps, combining quantitative and qualitative methods [69]. Methodological triangulation allows us to overcome the limitations of one approach by benefitting from the strengths of another.

\subsection{Quantitative study}

The quantitative analysis is based on a questionnaire sent to all the employees of WPI-iCeMS in late 2011 to obtain information on choice of research strategy, intellectual interest in TDR, the perceived contribution of TDR to their career, and their satisfaction with their organizational resources. This research design, a cross-sectional survey, is prone to common method bias, as constructs have been measured at the same point in time, location, and through the same medium. Furthermore, respondents may tend to provide socially desirable answers. We attempted to minimize this bias by adopting several devices: we structured the questionnaire so that the conceptual framework was not evident; we formulated a concise questionnaire and phrased the questions as precisely, neutrally, and unambiguously as possible; and we assured the respondents anonymity and encouraged them to provide honest answers [70].

The questionnaire was returned by 104 out of 177 scientists (for a response rate of 59\%); after excluding partially filled questionnaires, we obtained a valid sample of 96 respondents. We analyzed the data with descriptive statistical techniques and performed a multinomial logistic regression to identify the factors associated with different research strategies.

The dependent variable is based on a survey question that distinguishes among three research 
strategies: i) prioritization (the deliberate medium-to-long-term pursuit) of TDR; ii) prioritization of MDR; and iii) the attribution of the same importance to TDR and MDR. This survey adopted a broad definition of TDR, encompassing collaborative research and investigations across the disciplinary boundaries of the cell and material sciences. This notion of TDR is institutionalized among WPI-iCeMS' scientific community: integrating the cell and material sciences is one of the primary goals of the center and is regularly communicated and discussed at all levels of the organization. By contrast, MDR is intended as the pursuit of an investigation exclusively within a single disciplinary area.

We developed explanatory variables concerning four individual attitudes to the benefits of and barriers to TDR and to two organizational features related to TDR. These variables have been measured through a series of self-developed four-item Likert-type scales from "Strongly agree" (1) to "Strongly disagree" (4). ${ }^{1}$ We used self-developed scales because existing measures of attitudes to TDR did not seem to fit our purposes.

The belief that TDR is beneficial for idea generation is captured by a dummy variable taking a value of 1 if a scientist reported a level of attitude above the median (3) and 0 otherwise. The dummy intellectual challenges takes a value of 1 if the scientists attributed a value above 3 to the statements that TDR requires more study and that it requires more experimentation than MDR. A similar procedure was followed to build a dummy expressing collaboration barriers in TDR; in this case, the elementary dimensions are difficulties due to distance and alignment of priorities (both variables have a median value of 3). We capture the perceived bias of authoritative journals against TDR using a dummy taking the value of 1 if a respondent attributes a score above the median (2) to the statement "There is little space for TDR in top journals."

\footnotetext{
${ }^{1}$ In one case, we adopted a five-item scale, including the option "neutral."
} 
We measured satisfaction with four organizational resources- human, research funds, instruments and equipment, and information—and the authority to use them; based on this, we constructed a dummy taking the value of 1 for scores higher than the median (20). Organizational support was measured by a dummy taking a value of 1 if a respondent expressed a degree of satisfaction with the Joint Lab meeting, a flagship WPI-iCeMS activity intended to support TDR, above the median (3).

We finally used ranking, disciplinary specialization, and position in the job market as controls. The series of dummies describing the ranking of researchers distinguishes among Senior (i.e., full and associate professors), Assistant Professor and Lecturer, Post Doc, and Early Stage (i.e., graduate student, and PhD.). We placed all scientists into one of four disciplinary specializations: Cell Science, Materials Science, Chemistry, Physics and Other Disciplines, or to the Multidisciplinary category when they reported belonging to more than one. Job market distinguishes between scientists who are currently searching or considering searching for a new job (a dummy taking a value of 1 ) from those who are tenured, moving to another organization, or have just been hired by WPI-iCeMS.

\subsection{Qualitative study}

The second step of our analysis is a qualitative study aimed at enriching the results of the quantitative analysis with additional in-depth and contextualized insights into the actual understanding of TDR and of the reasons that drive scientists to undertake (or not undertake) this strategy. In this way, the case study analysis complements the findings from the questionnaire investigation.

We focused on scientists at the initial stages of their academic careers, since they are arguably experiencing the tensions among the desire to pursue a personal intellectual interest, accountability to their research leaders, and the wish to strengthen their scientific standing 
and thus increase their career opportunities. We interviewed three post docs and one assistant professor belonging to different research groups and different disciplinary specializations; genders were represented equally. A series of questions was developed based on the theoretical framework and the results of the quantitative analysis; these were shared with the interviewees in advance. The interviews lasted between thirty and sixty minutes.

\section{Results}

\subsection{Results of the survey}

First, we examine the choice of research strategy. The mission of and practices at WPI-iCeMS lead us to expect a prevalence of transdisciplinary-oriented scientists. Instead, we find that this strategy is prioritized by only $27.8 \%$ of researchers; the majority (55.2\%) attributes the same importance to TDR and MDR. Table 2, an overview of the research strategies by academic ranking, shows that senior and early-stage researchers prioritize TDR at the expense of MDR. An opposite tendency is found in the central classes of academic rankings, particularly among post docs, who definitely prioritize MDR. Even though the chi-squared test indicates that the differences between the rankings are not statistically significant, these results suggest that the propensity for TDR declines as a graduate student becomes decides to undertake an academic career.

$$
===\text { PLEASE, INSERT TABLE } 2 \text { ABOUT HERE }===
$$

Next, we examine how the perceived advantages of and barriers to TDR vary across research strategies and academic rankings. Forty-eight percent of respondents consider this approach beneficial for the generation of novel insights and ideas (see Table 3). In particular, these advantages are widely perceived among those who prioritize TDR (77\%), while they become 
less appreciated among those who also engage in MDR. The intellectual challenges of TDR are perceived less strongly than are its benefits for idea generation (31\% vs. 48\%); interestingly, those who pursue TDR are more aware of the challenges of this approach than are those who do not. The costs of collaborative research appear to be more relevant (41\%) and are associated with all three research strategies. Taking academic ranking into consideration, we find that senior scholars are more aware of the intellectual costs and advantages of TDR, while they seem more able to manage the collaborative research that threatens the scientists in all the other rankings. Looking at the perceived appeal of TDR in the scientific community, we observe that those who prioritize MDR believe that journals are biased against TDR, even though a considerable proportion of those who pursue TDR share the same belief. Such bias is particularly high among non-senior staff.

\section{=== PLEASE, INSERT TABLE 3 ABOUT HERE ===}

Table 4 presents data on the organizational dimension. Satisfaction with resources appears positively correlated with the undertaking of TDR; by contrast, satisfaction with support activities does not differ sharply across research strategies, while it grows along with academic ranking. We speculate that this result may express not only higher control over resources but also a higher commitment to the organization.

\section{$===$ PLEASE, INSERT TABLE 4 ABOUT HERE $===$}

Finally, we consider the differences across disciplinary areas; we are particularly interested in examining whether scientists who belong to more than one disciplinary area are more inclined towards TDR. Table 5 reveals that scientists specializing in cell biology show an evident propensity towards MDR, while TDR dominates the Physics and Other groups. Among scientists operating across multiple fields, TDR is quite common, though we find some who, surprisingly, prioritize MDR. We tend to rule out the possibility that these differences are 
driven by the distribution of junior scientists across disciplines, as this group accounts for about 70\% of the faculty in the Cell, Chemistry, and Physics and Other groups, who present quite different research strategy profiles.

\section{$===$ PLEASE, INSERT TABLE 5 ABOUT HERE $===$}

We carry out a multinomial logistic regression analysis to validate the results of the descriptive statistics. This econometric technique allows us to identify the factors associated with each research strategy by contrasting the strategies of prioritizing of TDR and MDR with the strategy of giving the same degree of attention to both approaches. ${ }^{2}$

Table 6 indicates that some factors that are positively associated with TDR are negatively associated with MDR, and vice versa. In particular, we find support for Proposition-1 concerning the role of perceived benefits for idea generation in the choice of research strategy: scientists who judge that TDR fosters idea generation are more inclined to prioritize this strategy, while those who do not share this belief tend to prioritize MDR. Turning to the barriers to TDR, we find that the factors associated with the execution of research projects (i.e., collaboration costs and intellectual effort) do not seem to affect prioritization, in contrast to the expectations of Proposition-2. Instead, consistent with Proposition-3, perceived publication opportunities matter: those who believe that journals are not biased against TDR prioritize this approach, while those who perceive this bias are more inclined towards MDR. It thus seems that choice of research strategy is driven by the benefits it can bring to the intellectual quality of the project and by expectations concerning potential recognition by the broader scientific community.

\footnotetext{
${ }^{2}$ Using a Hausman test, we ascertained that our regression model does not violate the independence of irrelevant alternative hypothesis. We can also exclude the possibility that our results are biased by multicollinearity, as the correlation between variables does not exceed 0.41 in absolute value, and the variance inflation factor is below 3 .
} 
Turning to the organizational level, we find that that degree of satisfaction with resources targeted to TDR is associated with the prioritization of a research strategy, in line with Proposition-4. Specifically, scientists who are satisfied with their resources tend to prioritize TDR, while those who show less satisfaction prioritize MDR. By contrast, satisfaction with the Joint Lab meeting does not seem to affect the choice of research strategy. We speculate that this result may indicate that organizational practices stimulating TDR are necessary for creating a favorable culture but that their relative influence on the choice of research strategy is weaker than are other management systems, such as the provision of resources targeted to TDR.

Taking the academic life cycle into consideration, we find partial support for Proposition-5 (which expects variations in interest in TDR across career stages). We find that interest in TDR does not follow a linear pattern throughout career stages: calculations on coefficients (not reported here) reveal that early-stage researchers present the highest interest in TDR among all academic rankings exhibiting a similar propensity for TDR. Instead, we find that propensity for MDR is intense among post docs and, to a lesser extent, assistant professors. Overall, the results seem to indicate that a negative attitude to TDR is typical of researchers who have completed their doctoral education and are at the beginning of their academic careers, arguably because of their lower endowment of scientific human capital and the stronger pressure to obtain tenure and further their careers. Early-stage researchers do not seem to perceive these pressures (yet) and are definitely open to pursuing this kind of investigation.

Finally, the results show that scientists belonging to multiple disciplinary communities are more inclined towards TDR than are those operating in cell biology and chemistry; however, chemists and material scientists are less inclined towards MDR than are those belonging to multiple communities. 


\section{$===$ PLEASE, INSERT TABLE 6 ABOUT HERE $===$}

\subsection{Analysis of interviews}

The four in-depth interviews on the motivations, values, and career perspectives of scientists at the beginning of their research careers provide valuable additional insights that are in line with the outcomes of the quantitative study.

All our informants show great interest in and excitement about TDR and recognize that WPIiCeMS provides a work environment very favorable to this research approach compared to other organizations in Japan. Undertaking TDR appears to be strongly related to the desire to acquire new knowledge. One of our interviewees strongly emphasizes this motivation: she framed her career pattern to pursue the opportunity to expand her competence portfolio to new areas only partially related to her previous experience. In fact, after acquiring expertise in a research field, she decided to work in a different discipline. This experience emphasizes the importance of idea generation and intrinsic motivation for TDR, in accordance with Proposition-1.

The team leaders of the three post docs play a significant role in the definition of their research strategy in terms of topics of investigation and methodologies. Team leaders influence post docs by giving advice and expert opinion and by framing the avenue of investigation for the whole group. The post docs who had experience in Japanese institutions recognize that the exercise of authority is much less pronounced than elsewhere. The assistant professor is in a very uncommon situation, being the leader of a little research unit and enjoying great autonomy concerning research choices. This finding appears particularly insightful, as it suggests that the analysis should be framed in terms of not only individual choice but also research team-level dynamics. 
All our interviewees shared the perception of TDR as a "risky" strategy. We asked our informants to identify the sources of risk. On the issue of publications, opinions differ. Some said that TDR studies are generally well-received by the academic community and may receive space and visibility in prestigious journals if they are of high quality. They also agree that senior scientists in their fields are not particularly conservative: they appreciate novelty, as long as it is methodologically sound. This view contrasts with the results of our quantitative analysis and the results of previous studies (e.g., [14]). However, we believe that this perception may be associated with the dynamics of the community in which our informants operate. In fact, another interviewee described the skepticism about TDR expressed by disciplinary scientists outside WPI-iCeMS, saying "My partners [from other disciplines] do not appreciate what I am doing."

Our informants emphasize another limit of TDR in terms of scientific productivity: they claim that MDR seems to guarantee scientists a more steady flow of publications. One informant emphasized that some research teams in other institutes implement a very paper-oriented approach: "scientists have in their mind all the pieces of the paper from the initial conception, [paradoxically] even before the experimental work is carried out." This is possible when the research strategy addresses small research gaps using traditional approaches; instead, TDR addresses broader research gaps, its research projects are more open-ended and produce results that are difficult to forecast in advance, and the experimental results are uncertain.

We found substantial agreement that TDR is less efficient than is the traditional approach because it entails a greater need for coordination among different specializations. When scientists trained in different specialties work together, they need to find a common communication ground in order to understand the priorities and techniques of different disciplines. Difficulties with coordination often delay the execution of a research project and can jeopardize the completion of the entire project. Poor communication emerges as a crucial 
cause of TDR projects' failure. These qualitative perspectives substantially mirror what Propositions- 2 and 3 identified as barriers to TDR but that did not emerge as significant in the quantitative analysis.

Regarding the effect of organizational features considered by Proposition-4, our informants agree that the culture of WPI-iCeMS is highly oriented towards TDR and that senior faculty supports this type of research, consistent with the quantitative results. The apparent contradiction between the mission and organizational practices at WPI-iCeMS (i.e., strongly emphasizing TDR but with the reward system and promotion criteria resting on academic excellence) challenges our interviewees. All our informants are aware that opportunities for their professional advancement depend on their ability to publish, and they do not perceive that the academic community has established evaluation criteria for researchers that are different from those of publications. They also believe that they are working on projects that may lead to high-quality publications but also to fewer publications than they would otherwise obtain by pursuing monodisciplinary projects.

It is important to relate these dynamics to opportunities for employability, as competition in the market for scientific positions is growing fiercer. Some of our informants are concerned about their career opportunities. One is aware of the difficulties of the job market, but this will not diminish her interest in and commitment to TDR: "I am not very ambitious. I am aware that maybe I am missing some opportunities. But I am a scientist, and learning new things is more important for me." This remark reminds us of the importance of considering the heterogeneity of career goals when analyzing choices of research strategy.

\section{Discussion and conclusion}

This paper has analyzed the relationship between research strategy and attitudes towards TDR and the perceptions of organizational incentives among employees at WPI-iCeMS, a 
Japanese university research center that aims to contribute to the development of a new scientific field across the cell and material sciences. We focus on the choices made by junior scientists, thus entering an important debate on the effects of incentive systems and research practices on the generation and re-generation of research capabilities. As the importance of TDR is expected to grow over the next decades, it is crucial to understand how research systems act to strengthen their capabilities in this area. The case of WPI-iCeMS appears particularly meaningful since the center aims to serve as an "incubator" of transdisciplinary capability.

Our results highlight that, although interest in TDR ranks high among all scientists and the organizational setting of the center reinforces this inclination, only a minority of scientists prioritize this approach while most pursue both transdisciplinary and monodisciplinary investigations. This evidence of the conflict between internal and external motivations in science contributes to the debate about the governance of scientific communities, in which the importance of motivations other than the pursuit of scientific excellence has only recently been explicitly acknowledged $[35,43,44,47]$.

Specifically, interest in TDR sharply declines when scientists complete their research training and enter an academic career: post docs and, to a lesser extent, assistant professors tend to prioritize monodisciplinary strategies. Our results do not provide a conclusive indication of the most challenging barriers to TDR, as both the perceived negative bias of established scholarly authorities and complexities in the execution of projects have been highlighted as relevant. The qualitative study suggests that this latter factor seems to dissuade junior scientists from prioritizing TDR more than do concerns over publication opportunities. This is in line with studies that emphasize the importance of intrinsic motivation to scientific work, i.e. the rewards associated with carrying on research according to the highest professional standards [35]. 
Our study concludes that TDR is perceived as a risky strategy in terms of future employability, as it seems to be associated with lower productivity in terms of publications, currently the key parameter of scholarly evaluation. Thus, scientists pursuing problem-oriented research in order to contribute to solving societal problems may be penalized in an open competition with scientists motivated by other goals. Although an analysis of publishing performance was outside the scope of our study, we believe that future research relying on bibliometric methods should provide quantitative proof of the actual penalty suffered by transdisciplinary scholars. Such evidence would be greatly useful in framing policies and organizational arrangements (e.g., the award of permanent positions) aimed at protecting scientists who pursue TDR from direct competition from colleagues focusing on MDR. Furthermore, in line with [71], we emphasize the importance of developing models of research management and evaluation that account for the specificities of TDR in order to overcome the paradox of the disciplinary assessment of interdisciplinary work [72]. In particular, we highlight the limits of evaluating research activities based on output measures such as the frequently used impact factor and publication frequency indicators. Maximizing these measures may have the undesirable effect of driving scientists to prefer conservative research strategies that will guarantee a stable flow of publications instead of privileging ambitious but risky projects. Activity-based measures seem more appropriate for evaluating scientists engaged in TDR. The possibility of offering scientists additional incentive schemes is particularly important in light of the institutional variety that is increasingly characterizing scientific systems worldwide. Such alternative incentive models appear particularly suitable for hybrid institutional settings such as mission-oriented national laboratories and university research centers.

Such arrangements might also help reduce the possible conflicts between junior and senior scholars working on the same team. We found that senior scientists are sensitive to organizational stimuli and thus encourage their teams to prioritize TDR. Managers of research 
organizations should make team leaders aware of the consequences of emphasizing TDR for their junior colleagues' employability; they could anticipate the possible negative impact of this approach and arrange a more competitive research portfolio. Our qualitative study also highlighted the role of team leaders in shaping post docs' strategies. A recent study [21] found that an important function of post doc employment is allowing scholars to formulate an autonomous research strategy by exploring and diversifying among problem areas. By contrast, the account of our informants' narratives indicated that the organizational structure of a mission-oriented organization with a clear identification of research group leaders may somewhat limit post docs' autonomy. This, again, points to research leaders' responsibility for managing their junior team members carefully.

Importantly, our study finds that scientific curiosity heavily influences the choice of research strategy and that motivational factors should be acknowledged along with career planning. Considering the trends towards problem-oriented, multi-institutional research, nurturing the interest of young scholars in TDR when they enter the academic profession appears critical if scientific systems are to build the capabilities necessary for achieving long-term scientific excellence $[15,16]$.

Finally, we consider the limitations of this study. First, this empirical work is based on the self-reported views of WPI-iCeMS members on their activities, goals, motivations, and practices. Although we took precautions to limit the bias associated with this research design, the heterogeneity of transdisciplinary practices [13] does not allow us to rule out that scientists may attribute a different meaning to the concept of TDR, thus potentially expressing their propensities and motivations for different practices. Therefore, it is important to emphasize that our study investigates researchers' subjective views on TDR. Future studies should follow a research design that allows a more precise and objective appreciation of the individual drivers of various forms of TDR. 
A second limitation concerns the generalization of our findings. We believe that this study is informative about the dynamics characterizing an institutional context in which science policy initiatives and research management aim to alter well-established incentives and the organizational culture within which knowledge production occurs. Therefore, we suggest that our results are not specific to the Japanese context but may also be relevant to other systems characterized by strong science policies aimed at changing the priorities of the academic profession. Finally, the object of our study concerns a precise area of research, the cell and material sciences. Great care should thus be taken in generalizing these results to TDR in other areas of investigation. However, we believe that our findings are applicable to other fields characterized by features similar to those of the cell and material sciences, such as the rapid development of new knowledge, the intensive use of research technology, strong linkages between basic and applied research, the strong potential for application to industrial use, and team-based research [1].

\section{Acknowledgements}

The authors would like to thank Kenji Watatani (McKinsey \& Company, Inc. Japan; formerly at WPI-iCeMS, Kyoto University) for his help with data collection. We are also grateful to Francesca Visintin and Daniel Pittino (University of Udine) and to the anonymous reviewers for their helpful comments. This study was supported by the Funding Program for Next Generation World-Leading Researchers by Japan's Cabinet Office and the Council for Science and Technology Policy (SS), the Japan Society for the Promotion of Science (JSPS) and the Ministry of Education, Culture, Sports, Science and Technology (MEXT) Grant-in-Aid for Scientific Research (SS, grant number 26285084) and the World Premium International Research Center Initiative (GL and SS). Any errors are the authors' own. 


\section{Appendix - Survey questions}

\section{How much are you satisfied with the support from WPI-iCeMS for each of these} items?

Possible answers:

1. Very satisfied; 2 . Rather satisfied; 3. Neutral; 4. Not so satisfied; 5. Not satisfied at all.

a. Human resources (project leader, other researchers, technician, assistant, etc.).

b. Funds (direct research expenses, indirect expenses and personnel costs).

c. Physical assets (space, instruments, equipment, facilities, etc.).

d. Information assets (databases, know-how, etc.) or opportunities for information exchange.

e. Authority to use the above resources.

\section{How much are you satisfied with the Joint Lab meetings?}

1. Very satisfied.

2. Rather satisfied.

3. Not so satisfied.

4. Not satisfied at all.

5. Never experienced them.

3. I would like to ask you about transdisciplinary research. Transdisciplinary research refers to the integration of the cell and the material sciences that may or may not involve collaborative research. Please select one of the following statements that effectively explains your views on transdisciplinary research.

1. I prioritize transdisciplinary research over established-area research.

2. I put the same emphasis on transdisciplinary research as on established-area research.

3. I prioritize established-area research over transdisciplinary research.

4. I do not proactively pursue transdisciplinary research.

4. What do you think about the features of transdisciplinary research listed below? Possible answers: 1 . Strongly agree; 2 . Somewhat agree; 3. Somewhat disagree; 4 . Do not agree at all.

a. It allows me to come up with new research ideas.

b. It takes more time to study basic knowledge in the new field.

c. It takes more time to conduct research/experiments than established areas.

d. It takes more time for coordination due to the many collaborative projects.

e. It is difficult to develop a track record due to the lack of major academic journals in the area.

f. It is hard to carry out research due to the large distances between collaborators.

\section{I would like to ask you about your career planning.}

Please select the statement that describes your next career steps.

1. I am tenured and not considering any particular next step.

2. I have already decided my next step (universities, institutes, companies etc.).

3. I am now job hunting (in process).

4. I am not acting but am searching/considering my next job with a plan of when to move. 
5. I have not decided when to move, but I'm considering my next career.

6. I do not have any plans about my next position at present (or I used to do job hunting but am not now).

\section{I would like to ask about your main research fields.}

1. Cell biology.

2. Materials science.

3. Chemistry.

4. Physics.

5. Others.

\section{I would like to ask about your position.}

1. Professor.

2. Associate professor.

3. Lecturer.

4. Post doc.

5. Research assistant.

6. Graduate student.

7. Masters student.

8. Other.

\section{Acknowledgements}

\section{References}

[1] A. Bonaccorsi, Search Regimes and the Industrial Dynamics of Science, Minerva. 46 (2008) 285-315.

[2] M. Gibbons, C. Limoges, H. Nowotny, S. Schwartzman, P. Scott, M. Trow, The new production of knowledge: The dynamics of science and research in contemporary societies, Sage, 1994.

[3] P. Nightingale, A. Scott, Peer review and the relevance gap: ten suggestions for policymakers, Sci. Public Policy. 34 (2007) 543-553.

[4] W.M. Cohen, R.R. Nelson, J.P. Walsh, Links and impacts: the influence of public research on industrial R\&D, Manage. Sci. 48 (2002) 1-23.

[5] M. Mobjörk, Consulting versus participatory transdisciplinarity: A refined classification of transdisciplinary research, Futures. 42 (2010) 866-873.

[6] C. Pohl, What is progress in transdisciplinary research?, Futures. 43 (2011) 618-626.

[7] F. Siedlok, P. Hibbert, The Organization of Interdisciplinary Research: Modes, Drivers and Barriers, Int. J. Manag. Rev. (2013). 
[8] J. Jacobs, S. Frickel, Interdisciplinarity: A Critical Assessment, Annu. Rev. Sociol. 35 (2009) 43-65.

[9] K. Huutoniemi, J.T. Klein, H. Bruun, J. Hukkinen, Analyzing interdisciplinarity: Typology and indicators, Res. Policy. 39 (2010) 79-88.

[10] J.T. Klein, Prospects for transdisciplinarity, Futures. 36 (2004) 515-526.

[11] D. Rhoten, S. Pfirman, Women in interdisciplinary science: Exploring preferences and consequences, Res. Policy. 36 (2007) 56-75.

[12] A. Buanes, S. Jentoft, Building bridges: Institutional perspectives on interdisciplinarity, Futures. 41 (2009) 446-454.

[13] W. Zierhofer, P. Burger, Disentangling Transdisciplinarity: An Analysis of Knowledge Integration in Problem-Oriented Research, Sci. Stud. (St. Bonaventure). 20 (2007) 5174.

[14] A. Bruce, C. Lyall, J. Tait, R. Williams, Interdisciplinary integration in Europe: the case of the Fifth Framework programme, Futures. 36 (2004) 457-470.

[15] C. Lyall, L.R. Meagher, A Masterclass in interdisciplinarity: Research into practice in training the next generation of interdisciplinary researchers, Futures. 44 (2012) 608617.

[16] H. Bridle, A. Vrieling, M. Cardillo, Y. Araya, L. Hinojosa, Preparing for an interdisciplinary future: A perspective from early-career researchers, Futures. 53 (2013) 22-32.

[17] B. Bozeman, C.P. Boardman, Managing the new multipurpose multidiscipline university research centers: Institutional innovation in the academic community, IBM Center for The Business of Government, Arlington, 2003.

[18] J. Bercovitz, M. Feldman, Academic Entrepreneurs: Organizational Change at the Individual Level, Organ. Sci. 19 (2008) 69-89.

[19] I. Rafols, L. Leydesdorff, A. O'Hare, P. Nightingale, A. Stirling, How journal rankings can suppress interdisciplinary research : A comparison between Innovation Studies and Business \& Management, Res. Policy. 41 (2012) 1262-1282.

[20] N. Carayol, J.-M. Dalle, Sequential problem choice and the reward system in Open Science, Struct. Chang. Econ. Dyn. 18 (2007) 167-191.

[21] E. Horlings, T. Gurney, Search strategies along the academic lifecycle, Scientometrics. 94 (2013) 1137-1160.

[22] J.M. Ziman, The problem of “problem choice," Minerva. 25 (1987) 92-106.

[23] P.E. Stephan, The Economics of Science, in: Handb. Econ. Innov. Vol. 1, 1st ed., Elsevier B.V., 2010: pp. 217-273. 
[24] R.K. Merton, Priorities in scientific discovery, Am. Sociol. Rev. 22 (1957) 635-659.

[25] P. Dasgupta, P.A. David, Toward a new economics of science,' Research Policy, 23, 487521., Res. Policy. 23 (1994) 487-521.

[26] M. Polanyi, The republic of science: its political and economic theory, Minerva. 1 (1962) 54-73.

[27] K. Urashima, Y. Yokoo, H. Nagano, S\&T policy and foresight investigation - impacts in Japan, Foresight. 14 (2012) 15-25.

[28] P. Gautam, R. Yanagiya, Reflection of cross-disciplinary research at Creative Research Institution (Hokkaido University) in the Web of Science database: appraisal and visualization using bibliometry, Scientometrics. 93 (2012) 101-111.

[29] T. Anzai, R. Kusama, H. Kodama, S. Sengoku, Holistic observation and monitoring of the impact of interdisciplinary academic research projects: An empirical assessment in Japan, Technovation. 32 (2012) 345-357.

[30] B.L. Ponomariov, C.P. Boardman, Influencing scientists' collaboration and productivity patterns through new institutions: University research centers and scientific and technical human capital, Res. Policy. 39 (2010) 613-624.

[31] M. Gaughan, B.L. Ponomariov, Faculty publication productivity, collaboration, and grants velocity: using curricula vitae to compare center-affiliated and unaffiliated scientists, Res. Eval. 17 (2008) 103-110.

[32] E. Corley, M. Gaughan, Scientists' Participation in University Research Centers: What are the Gender Differences?, J. Technol. Transf. 30 (2005) 371-381.

[33] C.P. Boardman, Government centrality to university-industry interactions: University research centers and the industry involvement of academic researchers, Res. Policy. 38 (2009) 1505-1516.

[34] J. Youtie, D. Libaers, B. Bozeman, Institutionalization of university research centers: The case of the National Cooperative Program in Infertility Research, Technovation. 26 (2006) 1055-1063.

[35] M. Osterloh, B.S. Frey, Research governance in academia: are there alternatives to academic rankings, 2009.

[36] B.S. Frey, F. Homberg, M. Osterloh, Organizational Control Systems and Pay-forPerformance in the Public Service, Organ. Stud. 34 (2013) 949-972.

[37] M. Jensen, W. Meckling, Theory of the firm: Managerial behavior, agency costs and ownership structure, J. Financ. Econ. 3 (1976) 305-360.

[38] D. Hicks, Performance-based university research funding systems, Res. Policy. 41 (2012) 251-261. 
[39] J. Taylor, The assessment of research quality in UK Universities: peer review or metrics?, Br. J. Manag. 22 (2011) 202-217.

[40] S. Smeenk, R. Eisinga, C. Teelken, J.A.C.M. Doorewaard, The effects of HRM practices and antecedents on organizational commitment among university employees, Int. J. Hum. Resour. Manag. 17 (2006) 2035-2054.

[41] S. Smeenk, C. Teelken, R. Eisinga, H. Doorewaard, Managerialism, Organizational Commitment, and Quality of Job Performances among European University Employees, Res. High. Educ. 50 (2009) 589-607.

[42] M. Van der Brink, B. Fruytier, M. Thunnissen, Talent management in academia: performance systems and HRM policies, Hum. Resour. Manag. J. in press (2012) 1-16.

[43] J. Duberley, Constructing Scientific Careers: Change, Continuity and Context, Organ. Stud. 27 (2006) 1131-1151.

[44] M. Mallon, J. Duberley, L. Cohen, Careers in public sector science: orientations and implications, R D Manag. 35 (2005) 395-407.

[45] D. Jindal-Snape, J.B. Snape, Motivation of scientists in a government research institute: Scientists' perceptions and the role of management, Manag. Decis. 44 (2006) 13251343.

[46] A. Lam, What motivates academic scientists to engage in research commercialization: "Gold", "ribbon" or "puzzle"?, Res. Policy. 40 (2011) 1354-1368.

[47] P.D. Este, O. Llopis, A. Yegros, Cognitive diversity, research excellence and awareness about the social impact of research, Leiden, 2013.

[48] I. van der Weijden, M. Verbree, P. van den Besselaar, From bench to bedside: The societal orientation of research leaders: The case of biomedical and health research in the Netherlands, Sci. Public Policy. 39 (2012) 285-303.

[49] G. Lauto, F. Valentin, How Large-Scale Research Facilities Connect to Global Research, Rev. Policy Res. 30 (2013) 381-408.

[50] I. Rafols, Strategies for knowledge acquistion in bionanotechnology, Innov. Eur. J. Soc. Sci. Res. 20 (2007) 395-412.

[51] J.N. Cummings, S. Kiesler, Coordination costs and project outcomes in multi-university collaborations, Res. Policy. 36 (2007) 1620-1634.

[52] P. Llerena, F. Meyer-Krahmer, Interdisciplinary research and the organizationof the university: General challenges and a case study, in: A. Geuna, A.J. Salter, W.E. Steinmueller (Eds.), Sci. Innov. Rethink. Ration. Funding Gov., Edward Elgar, Cheltenham, 2003.

[53] N. Carayol, T.U.N. Thi, Why do academic scientists engage in interdisciplinary research?, Res. Eval. 14 (2005) 70-79. 
[54] C. Pohl, Transdisciplinary collaboration in environmental research, Futures. 37 (2005) 1159-1178.

[55] F.J. van Rijnsoever, L.K. Hessels, Factors associated with disciplinary and interdisciplinary research collaboration, Res. Policy. 40 (2011) 463-472.

[56] J.N. Cummings, S. Kiesler, Collaborative Research Across Disciplinary and Organizational Boundaries, Soc. Stud. Sci. 35 (2005) 703-722.

[57] J.M. Levitt, M. Thelwall, Is Multidisciplinary Research More Highly Cited? A Macrolevel Study, J. Am. Soc. .... 59 (2008) 1973-1984.

[58] L.R. Gomez-Mejia, D.B. Balkin, Determinants of Faculty Pay: An Agency Theory Perspective, Acad. Manag. J. 35 (1992) 921-955.

[59] C.P. Boardman, E. Corley, University research centers and the composition of research collaborations, Res. Policy. 37 (2008) 900-913.

[60] C.P. Boardman, B.L. Ponomariov, Reward Systems and NSF University Research Centers: The Impact of Tenure on University Scientists' Valuation of Applied and Commercially Relevant Research, J. Higher Educ. 78 (2007) 51-70.

[61] M. Gaughan, B. Bozeman, Using curriculum vitae to compare some impacts of NSF research grants with research center funding, Res. Eval. 11 (2002) 17-26.

[62] B. Bozeman, J. Dietz, M. Gaughan, Scientific and Technical Human Capital: An Alternative Model for Research Evaluation, Int. J. Technol. Manag. 22 (2001) 716-740.

[63] S. Lee, B. Bozeman, The Impact of Research Collaboration on Scientific Productivity, Soc. Stud. Sci. 35 (2005) 673-702.

[64] D. Rhoten, A. Parker, Risks and rewards of an interdisciplinary research path, Science (80-. ). 306 (2004) 2046.

[65] M.M. Millar, Interdisciplinary research and the early career: The effect of interdisciplinary dissertation research on career placement and publication productivity of doctoral graduates in the sciences, Res. Policy. 42 (2013) 1152-1164.

[66] M. Sabharwal, Q. Hu, Participation in university-based research centers: Is it helping or hurting researchers?, Res. Policy. 42 (2013) 1301-1311.

[67] S.A. Bunton, W.T. Mallon, The Impact of Centers and Institutes on Faculty Life: Findings from a Study of Life Sciences Faculty at Research-Intensive Universities' Medical Schools, Innov. High. Educ. 32 (2007) 93-103.

[68] H. Kodama, K. Watatani, S. Sengoku, Competency-based assessment of academic interdisciplinary research and implication to university management, Res. Eval. 22 (2012) 93-104. 
[69] J.W. Creswell, Research Design: Qualitative, Quantitative, and Mixed Methods Approaches, Sage, Thousand Oaks, 2009.

[70] P.M. Podsakoff, S.B. MacKenzie, J.-Y. Lee, N.P. Podsakoff, Common method biases in behavioral research: a critical review of the literature and recommended remedies., J. Appl. Psychol. 88 (2003) 879-903.

[71] A.L. Carew, F. Wickson, The TD Wheel: A heuristic to shape, support and evaluate transdisciplinary research, Futures. 42 (2010) 1146-1155.

[72] V.B. Mansilla, Assessing expert interdisciplinary work at the frontier: an empirical exploration, Res. Eval. 15 (2006) 17-29. 


\section{Tables}

Table 1. Research propositions

Proposition-1: scientists' choice of a research strategy is associated with its perceived benefits in terms of idea generation.

Proposition-2: scientists' choice of a research strategy is associated with its perceived intellectual efforts and perceived problems with the management of collaborative research. Proposition-3: scientists' choice of a research strategy is associated with its perceived barriers in terms of publication opportunities.

Proposition-4: scientists' choice of a research strategy is influenced by the incentives and influence offered by their employing organization.

Proposition-5: scientists' choice of a research strategy varies across seniority levels, and more senior scholars tend to prioritize TDR over MDR.

Table 2. Relationship between prioritization of research strategy and academic title

\begin{tabular}{|l|c|c|c|c|c|}
\hline Research strategy & Senior & Assistant & Post Doc & Early Stage & Total \\
\hline TDR & $6(30 \%)$ & $8(28 \%)$ & $5(17 \%)$ & $7(41 \%)$ & $26(28 \%)$ \\
\hline Same importance & $13(65 \%)$ & $15(52 \%)$ & $17(57 \%)$ & $8(47 \%)$ & $53(55 \%)$ \\
\hline MDR & $1(5 \%)$ & $6(21 \%)$ & $8(27 \%)$ & $2(12 \%)$ & $17(18 \%)$ \\
\hline Total & 20 & 29 & 30 & 17 & 96 \\
\hline
\end{tabular}

Table 3. Number of scientists who perceive specific advantages and barriers to TDR, and relative weight in the classes defined by research strategy and academic ranking.

\begin{tabular}{|l|c|c|c|c|}
\hline & $\begin{array}{c}\text { Benefits for idea } \\
\text { generation }\end{array}$ & $\begin{array}{c}\text { Negative bias of } \\
\text { top journals }\end{array}$ & $\begin{array}{c}\text { Increased } \\
\text { intellectual effort }\end{array}$ & $\begin{array}{c}\text { Problems in } \\
\text { management of } \\
\text { collaborations }\end{array}$ \\
\hline Strategy & & & & \\
\hline TDR & $20(77 \%)$ & $10(38 \%)$ & $11(42 \%)$ & $11(42 \%)$ \\
\hline Same importance & $23(43 \%)$ & $22(42 \%)$ & $16(30 \%)$ & $20(38 \%)$ \\
\hline MDR & $3(18 \%)$ & $9(53 \%)$ & $3(18 \%)$ & $8(47 \%)$ \\
\hline Ranking & & & & \\
\hline Senior & $15(75 \%)$ & $5(25 \%)$ & $9(45 \%)$ & $5(25 \%)$ \\
\hline Assistant & $13(45 \%)$ & $13(45 \%)$ & $7(24 \%)$ & $14(48 \%)$ \\
\hline Post Doc & $11(37 \%)$ & $15(50 \%)$ & $8(27 \%)$ & $12(40 \%)$ \\
\hline Early Stage & $7(41 \%)$ & $8(47 \%)$ & $6(35 \%)$ & $8(47 \%)$ \\
\hline Total & $46(48 \%)$ & $41(43 \%)$ & $30(31 \%)$ & $39(41 \%)$ \\
\hline
\end{tabular}


Table 4. Number of scientists who are satisfied with organizational resources and support activities offered by WPIiCeMS, and relative weight in the classes defined by research strategy and academic ranking.

\begin{tabular}{|l|c|c|}
\hline & Satisfaction with resources & Satisfaction with support \\
\hline Strategy & & $10(38 \%)$ \\
\hline TDR & $17(65 \%)$ & $16(30 \%)$ \\
\hline Same importance & $22(42 \%)$ & $6(35 \%)$ \\
\hline MDR & $3(18 \%)$ & \\
\hline Ranking & & $10(50 \%)$ \\
\hline Senior & $9(45 \%)$ & $9(31 \%)$ \\
\hline Assistant & $13(45 \%)$ & $11(37 \%)$ \\
\hline Post Doc & $13(43 \%)$ & $2(12 \%)$ \\
\hline Early Stage & $7(41 \%)$ & $32(33 \%)$ \\
\hline Total & $42(43 \%)$ & \\
\hline
\end{tabular}

Table 5. Distribution of scientists by research strategy and disciplinary area.

\begin{tabular}{|l|c|c|c|c|c|c|}
\hline Strategy & Cell & Material & Chemistry & Physics/Other & Multiple & Total \\
\hline TDR & $3(9 \%)$ & $2(29 \%)$ & $5(26 \%)$ & $8(57 \%)$ & $8(36 \%)$ & $26(27 \%)$ \\
\hline Same importance & $18(53 \%)$ & $5(71 \%)$ & $14(74 \%)$ & $5(36 \%)$ & $11(50 \%)$ & $53(55 \%)$ \\
\hline MDR & $13(38 \%)$ & $0(0 \%)$ & $0(0 \%)$ & $1(7 \%)$ & $3(14 \%)$ & $17(18 \%)$ \\
\hline Total & 34 & 7 & 19 & 14 & 22 & 96 \\
\hline
\end{tabular}

Table 6. Results of multinomial logistic regression. Dependent variable: Research Strategy; baseline: "TDR and MDR have the same importance". Coefficients and significance level (in parentheses).

\begin{tabular}{|l|c|c|}
\hline & Prioritization of TDR & Prioritization of MDR \\
\hline Benefits of idea generation & $1.998^{* * *}(0.002)$ & $-1.421^{*}(0.060)$ \\
\hline Increased intellectual effort & $0.673(0.376)$ & $-0.810(0.525)$ \\
\hline $\begin{array}{l}\text { Problems with management of } \\
\text { collaborations }\end{array}$ & $0.031(0.961)$ & $-0.632(0.454)$ \\
\hline Negative bias of top journals & $-1.443^{* *}(0.024)$ & $1.377^{*}(0.072)$ \\
\hline Satisfaction with resources & $1.379^{*}(0.068)$ & $-2.837^{* *}(0.034)$ \\
\hline Satisfaction with support & $0.049(0.943)$ & $0.927(0.294)$ \\
\hline Ranking & & $1.915(0.130)$ \\
\hline Assistant & $0.936(0.312)$ & $2.283^{*}(0.062)$ \\
\hline Post Doc & $0.284(0.775)$ & $0.061(0.968)$ \\
\hline Early stage & $2.509^{* * *}(0.008)$ & $1.355(0.103)$ \\
\hline Disciplinary specialization & & $-39.495^{* * *}(0.000)$ \\
\hline Cell & $-1.792^{*}(0.052)$ & $-39.467^{* * *}(0.000)$ \\
\hline Material & $-0.182(0.883)$ & $0.066(0.967)$ \\
\hline Chemistry & $-1.863^{*}(0.072)$ & $-1.060(0.182)$ \\
\hline Physics \& Others & $1.415(0.117)$ & $-1.784(0.288)$ \\
\hline Presence in the job market & $-0.899(0.220)$ & \\
\hline Constant & $-2.200^{*}(0.063)$ & \\
\hline Cases & 96 & \\
\hline Log-likelihood & -58.514 & \\
\hline Wald test & $5657.92(0.000)$ & 0.383 \\
\hline Pseudo R2 & & \\
\hline
\end{tabular}

